\title{
EI SISTEMA FERROVIARIO DE LA REPÚBLICA ARGENTINA
}

\author{
CÁTEDRA: GEOGRAFÍA ARGENTINA \\ PROF. ANÍBAL MARCELO MIGNONE \\ 2012
}

Publicado en formato digital: Prof. Aníbal Marcelo MIGNONE. EI SISTEMA FERROVIARIO DE LA REPÚBLICA ARGENTINA. Resúmenes. Revista Geográfica Digital. IGUNNE. Facultad de Humanidades. UNNE. Año 10. № 19. Enero-Junio 2013. ISSN 1668-5180. Resistencia, Chaco.

En: http://hum.unne.edu.ar/revistas/geoweb/default.htm 


\section{LOS INICIOS}

- Revisar la historia del sistema ferroviario argentino implica remontarse al 29 de agosto de 1857 cuando un conjunto de empresarios construyeron la primera línea ferroviaria. El recorrido iba desde Plaza Lavalle hasta San José de Flores.

Posteriormente, iba desde el centro de la ciudad de Buenos Aires hasta los suburbios, a lo largo de $10 \mathrm{~km}$.

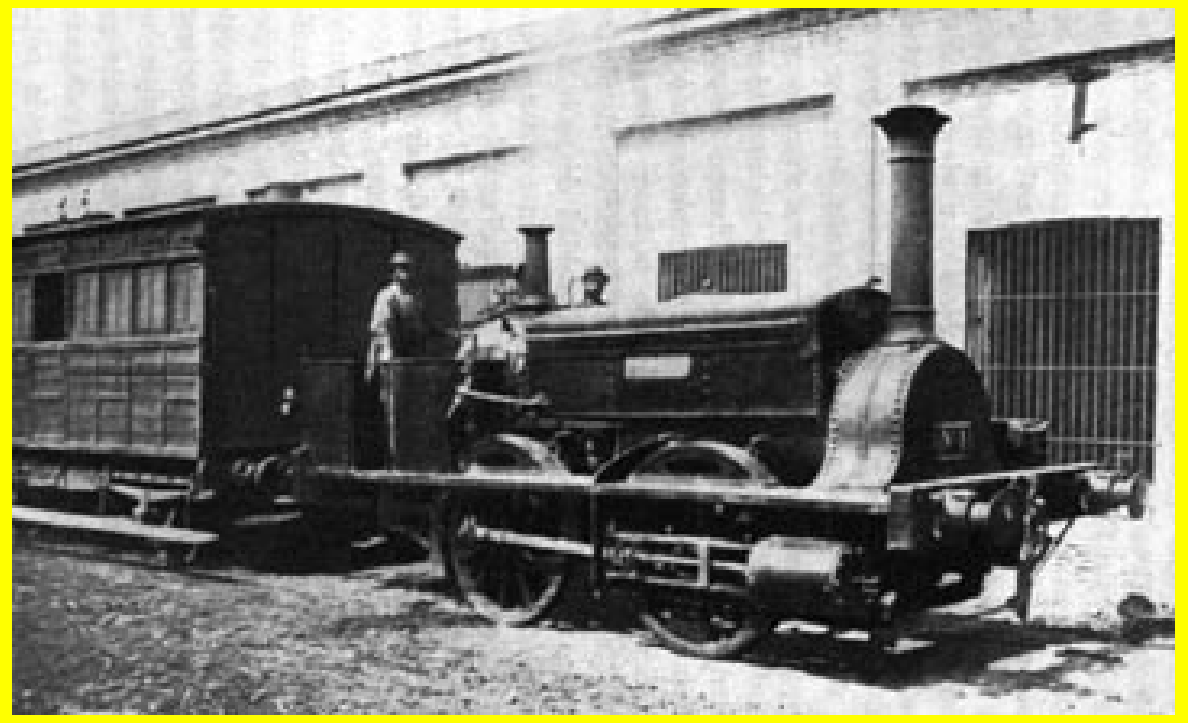

Primera locomotora "La Porteña" 
Entre 1862 y 1883 nacen cuatro líneas:

- Ferrocarril del Oeste (posteriormente Domingo F. Sarmiento) fue el primero en entrar en funcionamiento para cubrir (inicialmente) la distancia entre plaza Lavalle y Floresta, en Buenos Aires.

- Ferrocarril del Sud (después General Roca) llegó primero a Chascomús y, más tarde, a Las Flores, Bahía Blanca, Neuquén, Zapala y Mar del Plata, además de contar con varios ramales secundarios.

- Ferrocarril Central Argentino (de spués Gral. Mitre) tuvo sus inicios en Rosario, se extendió a Córdoba y después a Santa Fe y Tucumán; posteriormente, enlazó con Buenos Aires. Otra línea se extendía desde Río Cuarto hasta Mendoza.

- Ferrocarril Central Norte Argentino o Líneas del Estado (post. Gral Belgrano): partía de Córdoba hacia Salta y Jujuy. Luego fue a Chaco y Formosa. 


\section{EL APOGEO}

- En 1870 ya habían $722 \mathrm{~km}$ de vías. Para 1880 se habían construido $2516 \mathrm{~km}$ y en 1890 la extensión de la red era de $9342 \mathrm{~km}$.

- El período de 1900 a 1910 fue el de máxima construcción. A fines de la Primera Guerra Mundial se alcanzaron los 35.883 $\mathrm{km}$.

- Entre 1870 y 1914 se construyó la mayor parte con capital inglés, francés y argentino.

- Entre 1920 y 1930 el principal constructor fue el Estado, que construyó $4.238 \mathrm{~km}$ en las regiones más apartadas y menos atrayentes desde el punto de vista comercial.

Fuente: El ferrocarril en Argentina. En Internet: http://www.cnrt.gov.ar/infoferro/espanol/data/historia.htm 


\section{LA NACIONALIZACIÓN}

- El 1 de enero de 1947 todas las líneas y su propiedades anexas pasaron a dominio del estado nacional. En estos momentos, la red llega a ocupar el décimo puesto en el mundo, con cerca de 47.000 kilómetros de longitud

- Las diversas partes del sistema (unas 15 empresas ferroviarias por ese entonces) fueron reagrupadas en 6 líneas: Mitre, Roca, San Martín, Urquiza, Sarmiento y Belgrano).

- En 1965, se crea la Empresa Ferrocarriles del Estado Argentino (EFEA), posteriormente convertido en Ferrocarriles Argentinos (FA) como consolidación de las líneas mencionadas.

- Como herencia de las sucesivas iniciativas de construcción encaradas a través del tiempo, convivían tres trochas diferentes con una fuerte configuración radial hacia Buenos Aires que reducía sus posibilidades de integración.

Fuente: El ferrocarril en Argentina. En Internet: http://www.cnrt.gov.ar/infoferro/espanol/data/historia.htm 


\section{LAS TROCHAS}

- Trocha ancha $(1,676$ metros): Mitre, San Martín, Sarmiento y Roca

- Trocha media $(1,435$ metros): Urquiza

- Trocha angosta (1 metro): Belgrano

- Trocha económica 0 industrial $(0,75$ metros $)$

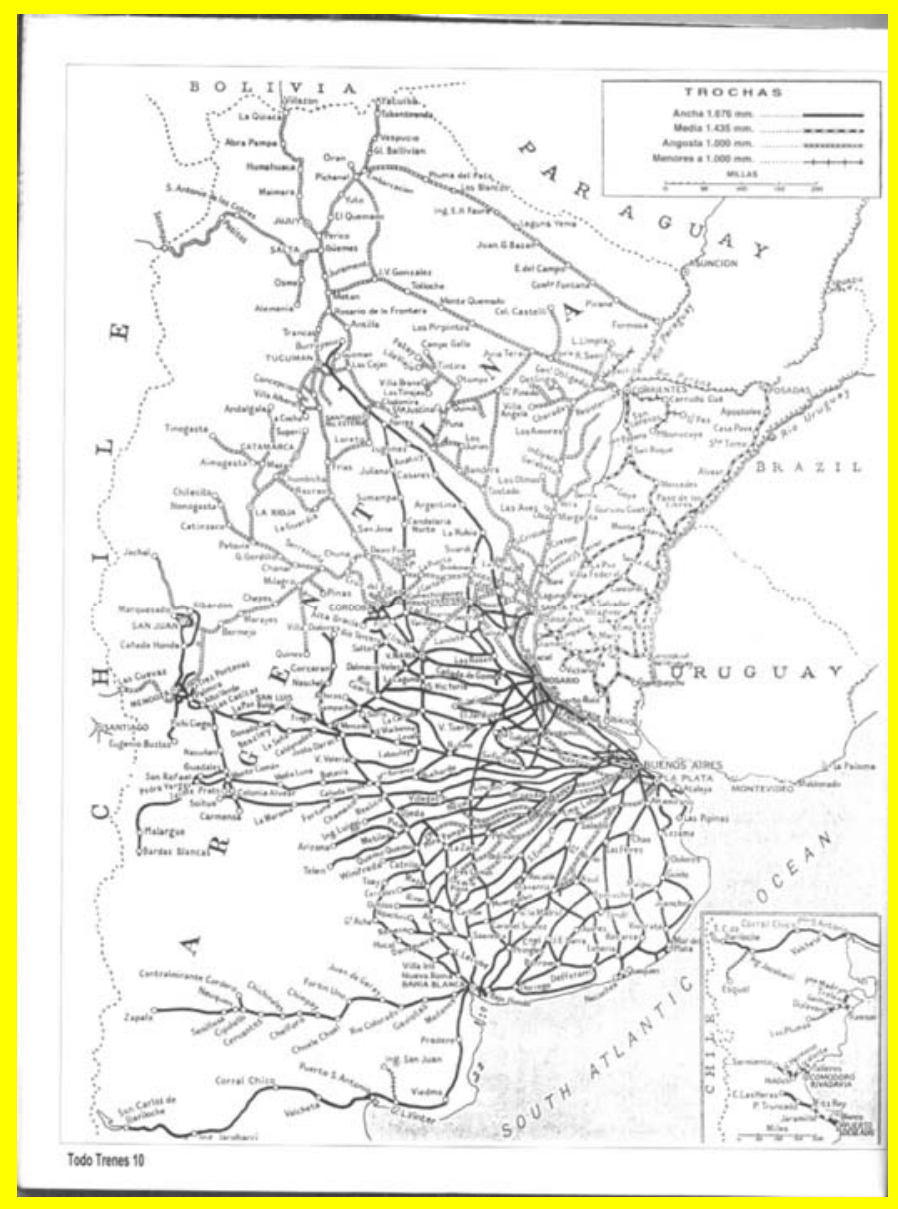

Fuente: http://www.es.wikipedia.org/wiki/Red_ferroviaria_argentina Publicado en formato digital: Prof. Aníbal Marcelo MIGNONE. EI SISTEMA FERROVIARIO DE LA REPÚBLICA ARGENTINA. Resúmenes. Revista Geográfica Digital. IGUNNE. Facultad de Humanidades. UNNE. Año 10. № 19. Enero-Junio 2013. ISSN 1668-5180. Resistencia, Chaco.

En: http://hum.unne.edu.ar/revistas/geoweb/default.htm 


\section{LA REGRESIÓN}

- En 1958 comienza un periodo que puede llamarse de regresión

- Las políticas a favor del desarrollo de la red caminera (transporte por carretera) dejaron de lado a la red ferroviaria. En vez de complementarse ambos sistemas, los mismos compitieron entre sí.

- Mientras en los países desarrollados se modernizaban los ferrocarriles, en Argentina estos fueron prácticamente abandonados, con la sola excepción de inversiones puntuales.

- En 1965, el ferrocarril transporta $25 \%$ del tráfico de cargas y el $18 \%$ de pasajeros. En 1980 , era de $8 \%$ y $7 \%$ respectivamente.

Fuente: El ferrocarril en Argentina. En Internet: http:/lwww.cnrt.gov.ar/infoferro/espanol/data/historia.htm 


\section{LA REGRESIÓN}

- La baja densidad de población en Argentina y la escasez de producciones voluminosas, fuertemente concentradas y demandantes de transporte a distancia, no permitieron determinar con claridad el rol que podía corresponderle al ferrocarril en el conjunto del mercado del transporte.

- La falta de objetivos se reflejó en una gestión estatal oscilante, muy presionada por los crecientes déficits operativos y de inversión, que se gravaron a lo largo del tiempo llevando a desarrollar planes de clausura y levantamiento de vías.

- En 1970, la red ferroviaria contaba con 41.596 kilómetros, para 1980 alcanzaba los $34.113 \mathrm{~km}$., y en 1990 tenía $31.793 \mathrm{~km}$.

- A fines de la década de 1980 , la necesidad de financiamiento para cubrir el déficit operativo y parte de las inversiones, se ubicaba en el orden de los $600 / 700$ millones de dólares anuales (1\% del PBI del momento). 


\section{Tráfico Ferroviario Argentino}

Millones Ton-km/Pas-km. Unidades de Tráfico = Pas-km + Ton-km

\begin{tabular}{|l|c|c|c|c|}
\hline & 1965 & 1975 & 1985 & 1990 \\
\hline Carga & 14.186 & 10.659 & 9.501 & 7.506 \\
\hline Pasajeros Interurbanos & 6.373 & 6.890 & 4.943 & 4.700 \\
\hline $\begin{array}{l}\text { Pasajeros de la Región } \\
\text { Metrop. de Bs.As. }\end{array}$ & 9.065 & 7.973 & 6.801 & 5.960 \\
\hline Total Unidades de Tráfico & 29.624 & 25.522 & 21.245 & 18.166 \\
\hline
\end{tabular}

Fuente: El ferrocarril en Argentina. En Internet: www.cnrt.gov.arlinfoferrolespanol/data/historia.htm 


\section{PROBLEMAS DEL SISTEMA FERROVIARIO}

De acuerdo con Roccatagliata (1997):

- Insuficiencia financiera crónica

- Profunda obsolescencia de la organización empresaria

- Pérdida moral e incentivo por parte del personal

- Falta de objetivos claros y de políticas de contenido empresarial

- Inercia de la empresa Ferrocarriles Argentinos frente al cambio 


\section{ALTERNATIVAS}

La gravedad del sistema ferroviaria obligaba a tomar una de estas tres alternativas (Roccatagliata, 1997):

- Clausurar los ferrocarriles

- Intentar recuperar la empresa Ferrocarriles Argentinos

- Intentar recuperar el modo de transporte ferroviario bajo nuevas modalidades 


\section{LA PRIVATIZACIÓN DEL SISTEMA FERROVIARIO}

- El gobierno de turno, optó por impulsar las privatizaciones. De esta manera llevó adelante un programa de reestructuración orientado a las tres unidades de negocio del sistema

- Red de mercancías (cargas)

- Red de pasajeros interurbanos

- Red de pasajeros de la región Metropolitana de Bs. As. 


\section{LAS CONCESIONES DE CARGA}

- Decisión estratégica a los efectos de su viabilidad global: la concesión no abarcaría al conjunto del sistema ferroviario en un único llamado a licitación para los $32.000 \mathrm{~km}$. de red en operaciones, sino que ésta sería concesionada por partes, tanto por:

- razones políticas: resultaría más aceptable entregar el sistema a varios operadores que a uno único,

- razones económicas: los recursos financieros necesarios por parte de operadores que tomaran sólo una porción del sistema serían sensiblemente menores, aumentando el número de potenciales grupos empresarios interesados. 


\section{LAS CONCESIONES DE CARGA}

- La concesión se inició con las líneas de cargas en las que se identificaron seis subsistemas a ser concesionadas por 30 años mediante licitación pública internacional bajo el concepto de concesión integral.

- Al no poder considerarse oferentes para la ex línea Belgrano, por no ajustarse a los requisitos, se conformó una Sociedad Anónima del Estado que operaría con las mismas características de las otras concesiones de carga pero con un subsidio explícito para inversiones de 50 millones de pesos anuales (efectivizado en forma parcial) 


\section{LAS EMPRESAS}

- Nuevo Central Argentino S.A. (NCA, $4.512 \mathrm{~km}$ ), que conecta Buenos Aires con Rosario, Santa Fe, Córdoba, Tucumán, Río IV y Santiago del Estero (La Banda);

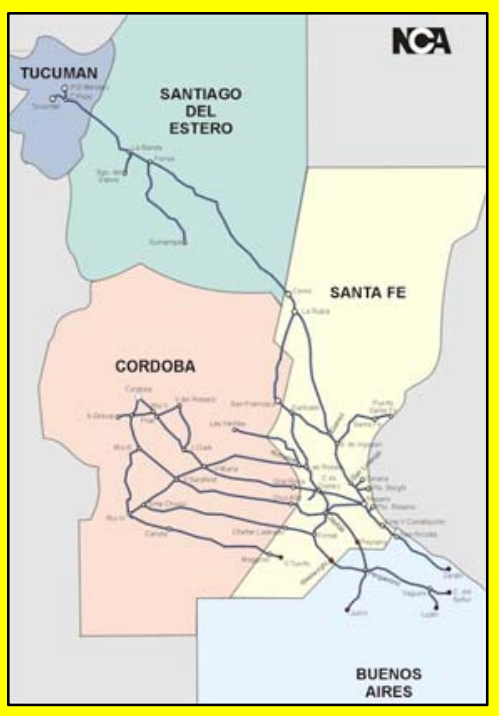

- América Latina Logística (ex Buenos Aires al Pacífico S.A, $5.254 \mathrm{~km}$ ), que enlaza Buenos Aires con Junín, Rufino, San Luis, Mendoza, San Juan, San Rafael y accede al puerto de Rosario;

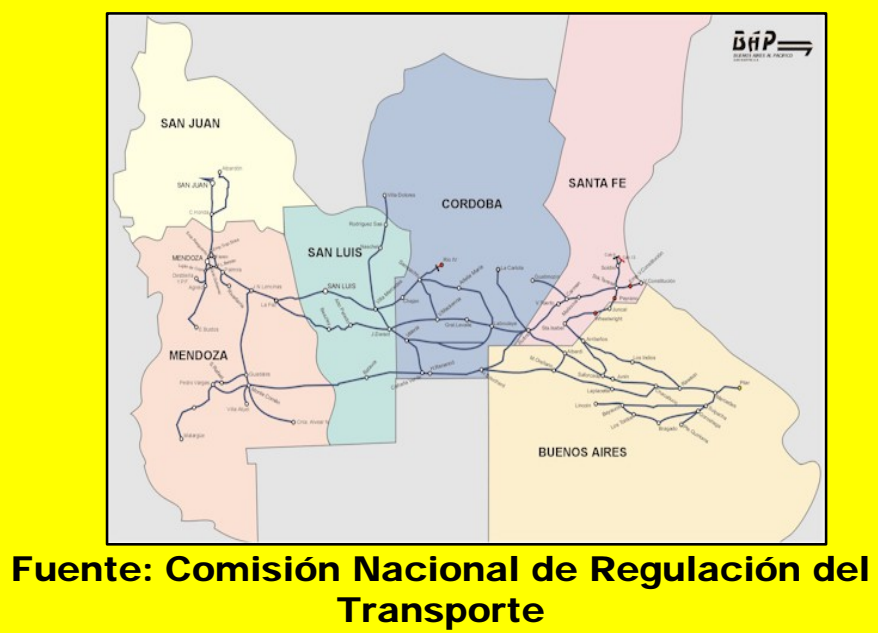




\section{LAS EMPRESAS}

Ferrosur Roca S.A. (3.342 km), que comunica Buenos Aires con Necochea-Quequén, Tandil, Olavarría, Bahía Blanca, Neuquén y Zapala;

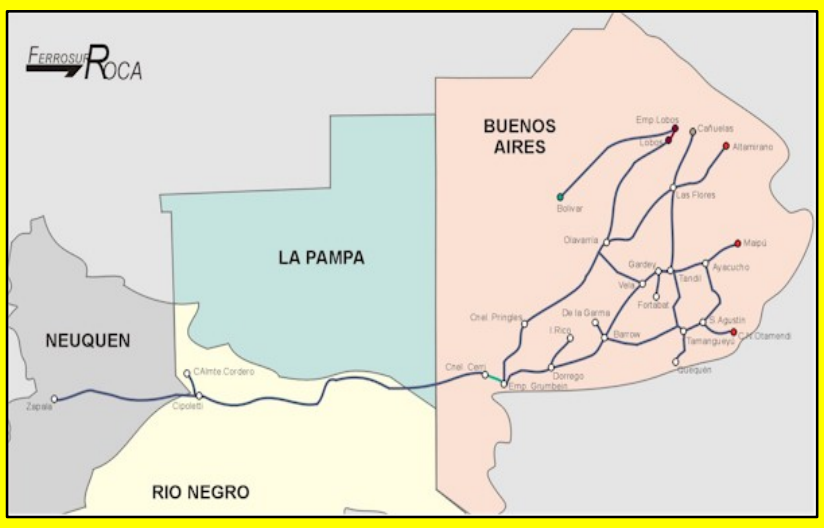

Ferroexpreso Pampeano S.A. (FEPSA, $5.094 \mathrm{~km}$ ): conecta a los puertos del complejo San Martín-Rosario con Bahía Blanca por medio de dos líneas troncales y varios ramales; presta servicios a acopiadores y explotadores de cereales.

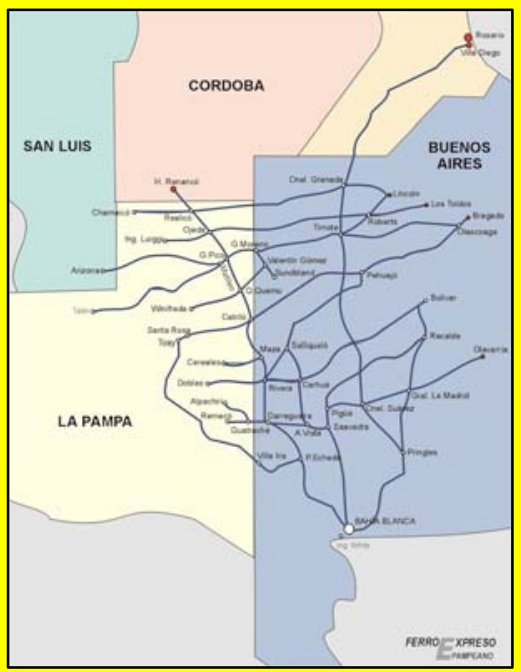

Fuente: Comisión Nacional de Regulación del Transporte 


\section{LAS EMPRESAS}

- América Latina Logística Mesopotámica S.A. (ex Ferrocarril Mesopotámico S.A., $2.739 \mathrm{~km}$ ), que enlaza Buenos Aires con Rojas, Concordia, Paraná, Paso de los Libres, Monte Caseros, Corrientes y Posadas;

- Belgrano Cargas S.A. (10.841 km), que comunica Buenos Aires con Rosario, Santa Fe, Córdoba, Resistencia, Salta, Jujuy, Tucumán, Catamarca, San Juan y Mendoza, y la localidad de Salta con Formosa.
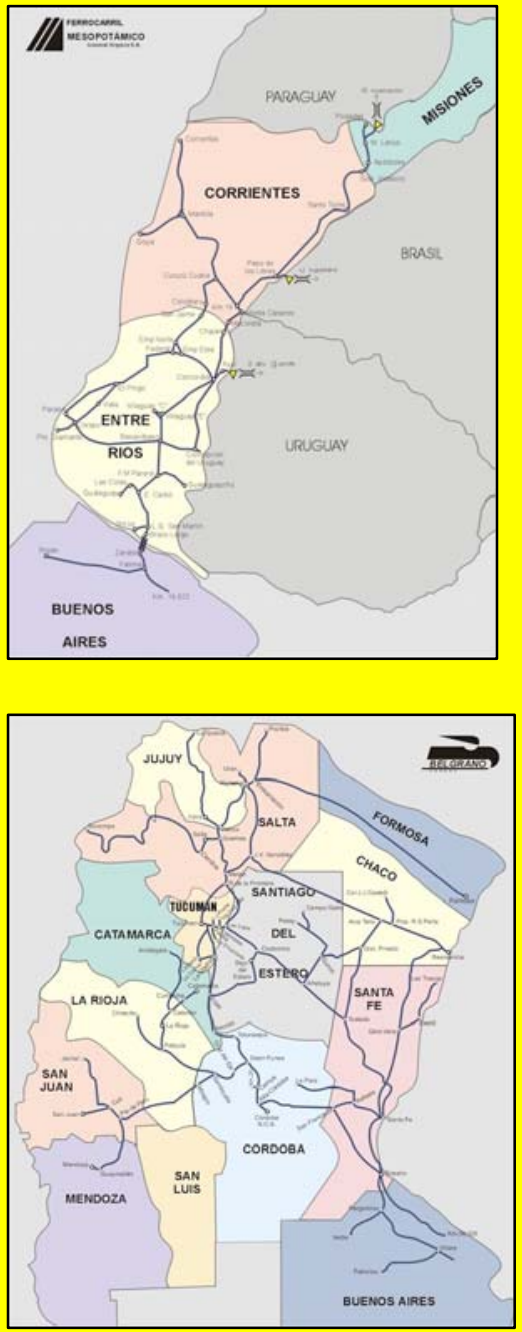

Fuente: Comisión Nacional de Regulación del Transporte 


\section{Red Ferroviaria Argentina}

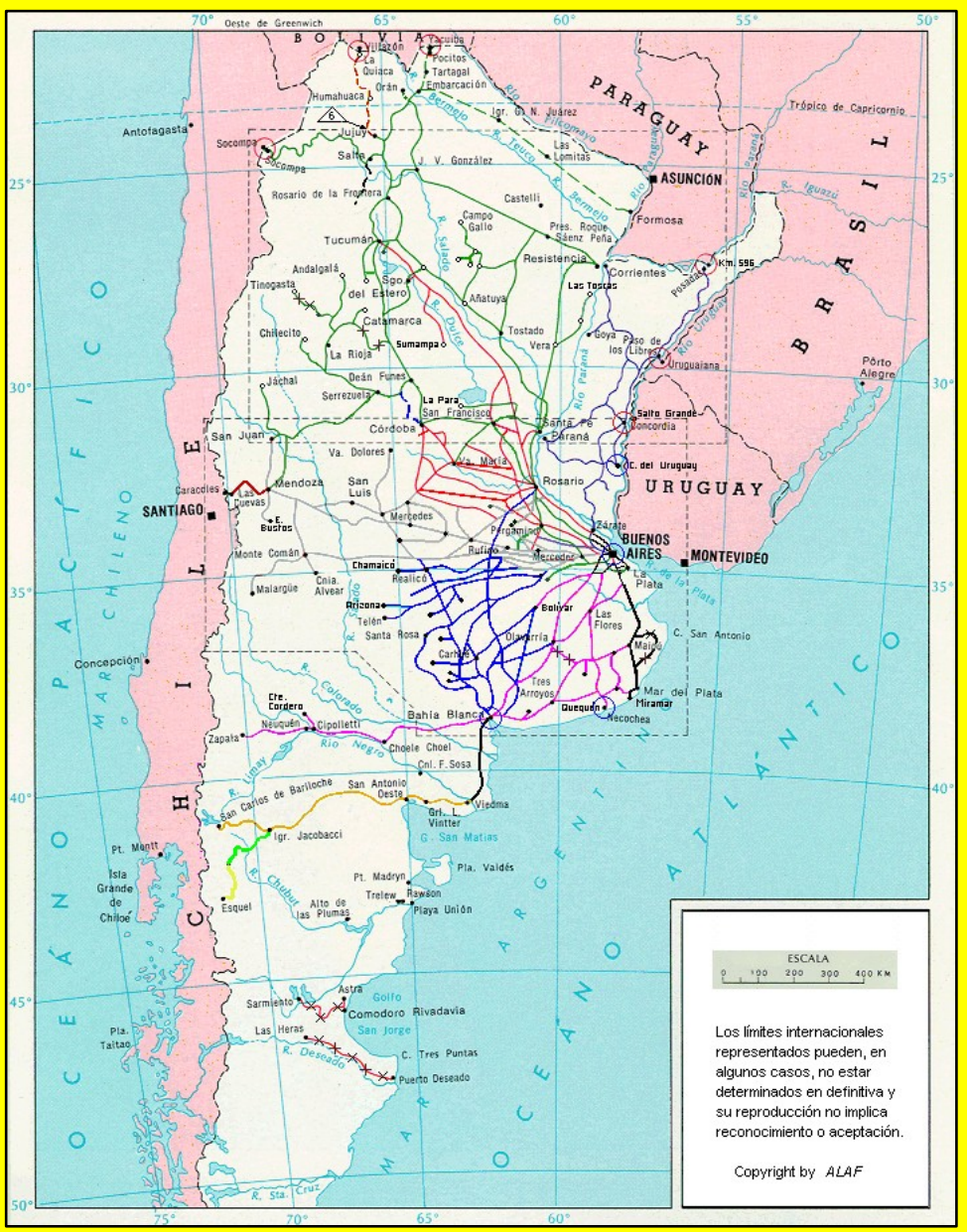

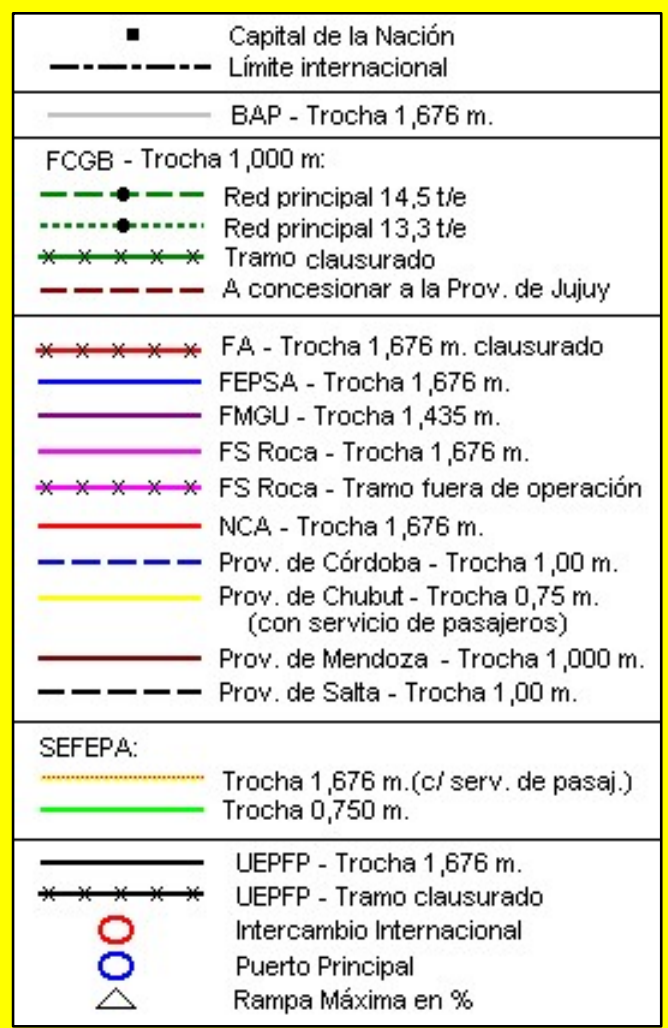

Fuente: Comisión Nacional de Regulación del Transporte.

http://www.cnrt.gov.ar/infoferrolespanol/data/map_cro_lin/d_total_mapa.htm

Publicado en formato digital: Prof. Aníbal Marcelo MIGNONE. EI SISTEMA FERROVIARIO DE LA REPÚBLICA ARGENTINA. Resúmenes. Revista Geográfica Digital. IGUNNE. Facultad de Humanidades. UNNE. Año 10. № 19. Enero-Junio 2013. ISSN 1668-5180. Resistencia, Chaco.

En: http://hum.unne.edu.ar/revistas/geoweb/default.htm 


\section{CARACTERÍSTICAS DE LAS CONCESIONES}

- Las concesiones son por treinta años con opción a diez años más.

- Las concesionarias son en general grupos económicos que manejan las empresas cementeras o agroindustriales.

- Del total de las vías férreas: $13787 \mathrm{Km}$ Bs. As., $5285 \mathrm{Km}$ Santa Fe, Entre Ríos $1929 \mathrm{Km}$, Córdoba 5089 y La Pampa 1487. Se concentra más del $70 \%$ del total de las vías férreas del país.

- Las cifras resaltan la importancia del ferrocarril en la región, con el objetivo de vincular las áreas productivas con los puertos del área pampeana.

- De allí la distribución en abanico con centro en Capital Federal y otros dos nudos ferroviarios importantes: Rosario y Bahía Blanca. 


\section{CARACTERÍSTICAS DE LAS CONCESIONES}

- La mayor parte del tráfico corresponde a bienes como: granos, derivados del petróleo, minerales, bebidas y aceites, entre otros.

- En la década del '90, se incrementó la modalidad correspondiente al uso de los contenedores.

- Las redes no concesionadas fueron ofrecidas a las provincias.

- Los ramales que no fueron tomados, fueron clausurados. 


\section{CARACTERÍSTICAS DE LAS CONCESIONES}

- Si bien existieron límites en cuanto a las tarifas de los operadores tenían que cobrar, en la práctica se trató de prestaciones totalmente desreguladas (no existen obligaciones del servicio público).

- Los concesionarios solamente tenían que cumplir el plan de inversiones prometido y mantener niveles mínimos de servicio de la infraestructura (cumplido en forma parcial).

Fuente: El ferrocarril en Argentina. En Internet: http://www.cnrt.gov.arlinfoferro/espanol/data/historia.htm 


\section{Belgrano Cargas S.A.}

- En 1993 se creó la empresa pública Ferrocarril General Belgrano S.A. Ejecutó un plan de inversiones, pero no mejoró el resultado de la empresa.

- En 1998, transportó solamente 1.500 .000 toneladas.

- Ese mismo año, se adjudicó en forma directa y por 30 años, la concesión de la empresa, cuya gestión quedó a cargo de los mismos funcionarios, pero no consiguieron mejorar los resultados, a pesar del desarrollo sojero que desplazó la frontera agrícola.

- En 2005, el tráfico se redujo a 600.000 toneladas, y funcionaba con menos de una docena de locomotoras. 


\section{Belgrano Cargas S.A.}

- En abril de 2006 se declara el "estado de emergencia" de la línea Belgrano Cargas S.A.

- En julio del mismo año, el Gobierno nacional resolvió otorgarle el manejo del ferrocarril a Sociedad Operadora de Emergencia Sociedad Anónima (SOE), encabezada por el grupo Macri y la firma china Sonhe Hopefull. También integran la sociedad el grupo Roggio, la empresa EMEPA, el gremio de la Unión Ferroviaria (UF), La Fraternidad y la Mutual de Camioneros 15 de Diciembre que conduce Hugo Moyano.

- La nueva administradora recibía un subsidio operativo mensual para pagar los sueldos, las reparaciones del material tractivo y rodante y realizar las inversiones del programa de emergencia. 


\section{Belgrano Cargas S.A.}

- La nueva gestión y las condiciones económicas mejoraron algo.

- En 2010 se transportó 1.200 .000 toneladas y se incrementó el número de locomotoras (31).

- La inversión en infraestructura quedó en manos de la Administración de Infraestructuras Ferroviarias Sociedad Anónima del Estado (ADIF), que comenzó a realizar obras de reemplazo de vías en algunos tramos de la red.

- En octubre de 2012 , se produce la intervención del SOE, como paso para un proceso de reestatización del Belgrano Cargas.

Fuente: Ministerio del Interior y Transportes de la República Argentina.

http://www.transporte.gov.ar/content/acciones_reconstrucciondelr_1309992274I

Publicado en formato digital: Prof. Aníbal Marcelo MIGNONE. EI SISTEMA FERROVIARIO DE LA REPÚBLICA ARGENTINA. Resúmenes. Revista Geográfica Digital. IGUNNE. Facultad de Humanidades. UNNE. Año 10. № 19. Enero-Junio 2013. ISSN 1668-5180. Resistencia, Chaco.

En: http://hum.unne.edu.ar/revistas/geoweb/default.htm 


\section{Corredores estratégicos Belgrano Cargas}

- Corredor Salta - Barranqueras - Rosario

- Ramal de conexión internacional C-C14 -C15

- Ramal C25

- Ramal Tostado - Las Cejas en Santiago del Estero

- Ramales Mineros

- Corredor Central Córdoba

- Vinculación Ferro portuaria Rosario - Zárate - La Plata 


\section{EL SERVICIO INTERURBANO DE PASAJEROS POR FERROCARRILES}

- Este servicio experimentó una reducción significativa de su nivel de actividad desde 1990 , por decisión del gobierno nacional de transferir a las jurisdicciones provinciales la responsabilidad por la prestación de los servicios.

- Actualmente, la mayoría de los operadores pertenecen a estados provinciales. En algunos casos se trata de prestaciones que emplean infraestructura perteneciente a operadores de carga, contra pago de peaje.

- No existió incorporación de tecnología, nuevo material rodante o renovación de infraestructura. En todo caso, se adquirió material usado, principalmente de España (caso de SOF.SE).

- En septiembre de 2011 , se inaugura el servicio entre Argentina y Uruguay, denominado "Tren de los Pueblos Libres", QUE va desde Concordia a Salto. Funciona esporádicamente y con dificultades, hasta que se suspende el servicio a mediados de 2012. 


\section{TRANSPORTE INTERURBANO DE PASAJEROS}

- U.E.P.F.P. (Pcia de Buenos Aires)

- SEFePA S.A. (Pcia de Río Negro)

- Pcia. de Tucumán

- Viejo Expreso Patagónico (La Trochita- Chubut)

- F.C Córdoba: Ramal A1- Central S.A.

- FEMED S.A. (Córdoba)

- Tren de Las Nubes (Salta)

- SOFSE (ex SEFECHA) Interurbano y Metropolitano (Chaco)

- T.B.A. (Retiro - Rosario- Santa Fe

- TEA (Trenes Especiales Argentinos) "El Gran Capitán (paralizado en 2012)

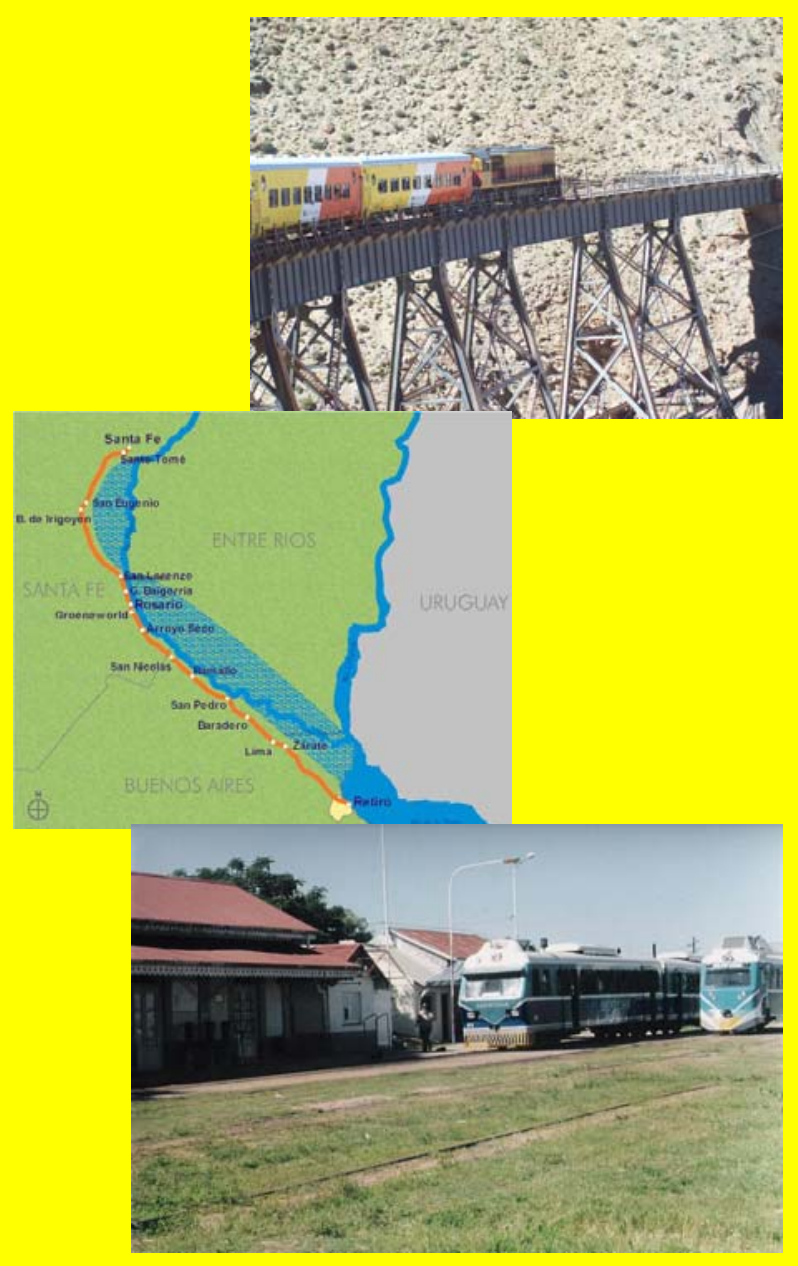

Publicado en formato digital: Prof. Aníbal Marcelo MIGNONE. EI SISTEMA FERROVIARIO DE LA REPÚBLICA ARGENTINA. Resúmenes. Revista Geográfica Digital. IGUNNE. Facultad de Humanidades. UNNE. Año 10. № 19. Enero-Junio 2013. ISSN 1668-5180. Resistencia, Chaco.

En: http://hum.unne.edu.ar/revistas/geoweb/default.htm 


\section{EL SISTEMA FERROVIARIO DE PASAJEROS DE LA RMBA}

- El gobierno nacional decide en marzo de 1991, separar los servicios ferroviarios de pasajeros de la Región Metropolitana de Buenos Aires del resto del sistema ferroviario argentino.

- Se crea Ferrocarriles Metropolitanos Sociedad Anónima (FE.ME.SA.), con la finalidad exclusiva de prestar los servicios de pasajeros de la región.

- La decisión del Gobierno Nacional de convocar al sector privado, estuvo destinada a rescatar y jerarquizar su rol dentro del sistema de transporte público de la Región así como a mejorar su eficiencia y calidad de servicio.

- A los efectos del llamado a licitación se definieron 7 Grupos de Servicios, a ser licitados individualmente, (tradicional gerenciamiento por "línea").

- A esta división, se agregó al Grupo de Servicios 3-Línea Urquiza, la red de subterráneos de Buenos Aires, por su compatibilidad técnica y conexión física con la línea Urquiza.

Fuente: El ferrocarril en Argentina. En Internet: http://www.cnrt.gov.ar/infoferro/espanol/data/historia.htm 


\section{EL SISTEMA FERROVIARIO DE PASAJEROS DE LA RMBA}

- Desde el año 2006, se han emitido denuncias por deficiencias en los servicios de trenes que circulan por Buenos Aires (sistema de señalamiento, formaciones "reformadas", etc).

- Las cancelaciones de servicios, los accidentes se hicieron cotidianos. El dinero que recibían las empresas no se trasladaba al mantenimiento del sistema ferroviario.

- Las empresas privatizadas tomaron una modalidad por todos los trabajadores conocida, desguazar formaciones paradas y con esos repuestos poner a funcionar otras formaciones, creando un círculo vicioso que Ilevaba a que cada vez hubiera menos formaciones por el deterioro y la falta de repuestos 


\section{LAS CONCESIONES}

- Metrovías S.A.: línea Urquiza (ramal Federico Lacroze-Gral. Lemos) y Red de Subterráneos de Buenos Aires.

- Unidad de Gestión Operativa Ferroviaria (UGOFE S.A.): línea Roca (ramales Constitución-La Plata/Glew/Ezeiza/Temperley; Ezeiza-Cañuelas; Glew-Korn; Temperley-Gutierrez/Haedo), línea San Martín; línea Belgrano Sur (ramales Buenos AiresGozalez Catán; Pte. Alsina-Aldo Bonzi; Tapiales-Marinos)

- Unidad de Gestión Operativa Mitre Sarmiento (UGOMS): línea Mitre (ramales retiro-J.L.Suarez; Retiro-Tigre; Retiro-Mitre; Victoria-Capilla; Villa Ballester-Zárate); línea SARMIENTO (ramales Once-Moreno; Moreno-Mercedes; Merlo-Lobos)

- Ferrovías S.A.C.: línea Belgrano Norte (ramal Retiro-Villa Rosa) 


\section{Bibliografía}

- Comisión Nacional de Regulación del Transporte. s/f. El ferrocarril en Argentina. Consultado el $\mathbf{3 0}$ de febrero de 2012. En Internet: http://www.cnrt.gov.ar/infoferro/espanol/data/historia.htm

- El sistema ferroviario en la República Argentina. Consultado el 30 de octubre de 2012. Disponible en Internet: http://www.apie.com.ar/articulos/SISTEMA\%20FERROVIARIO.pdf

- López, Mario y Jorge Waddell (comp.). 2007. Nueva historia del ferrocarril en la Argentina. 150 años de política ferroviaria. Ediciones Lumiere S. A., Buenos Aires.

- Müller, Alberto. 2004. "Reforma y privatización en el sector transporte: reseña y balance preliminar". En Revista Desarrollo Económico N² 173. Vol.44. IDES. Buenos Aires.

- Red ferroviaria Argentina. Consultado el 06 de noviembre de 2012. Disponible en Internet: http://es.wikipedia.org/wiki/Red ferroviaria argentina

- Roccatagliata, Juan. 1997. "El transporte. Algunas consideraciones actuales". En: Geografía Económica Argentina. Rocatagliata, Juan. 2a Edición. El Ateneo, Buenos Aires. Pp: 227- 267.

- Scalabrini Ortiz, Raúl. 2009. Los ferrocarriles deben ser argentinos. Editorial Lancelot, Buenos Aires. 